\title{
Derrame pleural durante la gestación
}

\author{
Pleural effusion during pregnancy
}

\author{
Joaquín Serrano Arreba', Fernanda López-Roibal Mourelle², \\ Javier Porteiro Sánchez ${ }^{1}$, Héctor Meijide Míguez ${ }^{1}$ \\ ${ }^{1}$ Servicio de Medicina Interna, ${ }^{2}$ Servicio de Ginecología, Hospital Quirónsalud A Coruña.
}

\section{Resumen}

La presencia de un exudado linfocitario con ADA elevado, especialmente en un paciente joven y en área endémica, siempre sugiere un diagnóstico de alta probabilidad de tuberculosis pleural. En cualquier caso sabemos que existen otras entidades que, aunque improbables, deben ser incluidas dentro del diagnóstico diferencial. En consecuencia es frecuente que al clínico se plantee la duda de cuando asumir un diagnóstico altamente probable 0 profundizar con el estudio etiológico y realizar una biopsia pleural.

A continuación presentamos el caso de una gestante con un exudado linfocitario con ADA elevado así como cual debe ser su manejo diagnóstico y terapéutico

Palabras clave: Derrame pleural. Gestación. Exudado linfocitario. ADA.

\section{Introducción}

La presencia de un exudado linfocitario con ADA elevado, especialmente en un paciente joven y en área endémica, siempre sugiere un diagnóstico de alta probabilidad de tuberculosis pleural. En cualquier caso sabemos que existen otras entidades que, aunque improbables, deben ser incluidas dentro del diagnóstico diferencial. Presentamos un caso que traduce una una realidad a la que los clínicos nos enfrentamos con frecuencia asi como las controversias en el manejo del mismo.

\section{Caso clínico}

Mujer de 32 años alérgica a Penicilina seguida en consultas externas de Ginecología con gestación evolutiva normal hasta la semana 24 en la que se detecta una disminución en la curva de crecimiento fetal (percentil 10).

Valorada en consultas externas de Medicina interna en tercer trimestre de gestación por cuadro subagudo (8 semanas de evolución) de tos escasamente productiva, astenia, anorexia, febrícula, sudoración nocturna y pérdida de peso $(3 \mathrm{Kg})$. Fue tratada de forma ambulatoria empíricamente con Azitromicina sin respuesta. Las últimas semanas desarrolló disnea de moderados esfuerzos y un episodio de hemoptisis leve-moderada.

La exploración física reveló disnea de mínimos esfuerzos con saturación de oxígeno basal del 93\%, hipofonesis en 2/3 inferiores del hemitórax izquierdo y febrícula $\left(37.6^{\circ} \mathrm{C}\right)$. TA $132 / 85 \mathrm{mmHg}$ y FC $105 \mathrm{lpm}$. No se palparon adenopatías a ningún nivel ni se objetivó ingurgitación yugular. La auscultación cardiaca fue normal y no presentaba edema periférico. La exploración abdominal fue concordante con la gestación.

La radiografía de tórax (fig 1) en dos proyecciones (posteroanterior y lateral) confirmó la presencia de un significativo derrame pleural izquierdo. Se decidió ingreso para completar los estudios diagnósticos y mantener vigilancia estrecha de la madre y el feto.

Correspondencia: jsarreba@gmail.com

Como citar este artículo: Serrano Arreba J, López-Roibal Mourelle F, Porteiro Sánchez J, Meijide Míguez H. Derrame pleural durante la gestación Pleural effusion during pregnancy. Galicia Clin 2018; 79 (2): 50-52 Recibido: 10/11/2017 Aceptado: 11/02/2018

\begin{abstract}
High ADA lymphocyte exudate, especially in a young patient in an endemic area, always suggests a diagnosis of pleural tuberculosis. In any case, we know that there are other entities that, although unlikely, should be included in the differential diagnosis. Consequently, it is common for the clinician to raise the question of when to assume a highly probable diagnosis or when is necessary to perform a pleural biopsy.

We present the case of a pregnant with a high ADA lymphocyte exudate, as well as what should be its diagnostic and therapeutic management.
\end{abstract}

Keywords: Pleural effusion. Pregnancy. Lymphocyte exudate. ADA.

Fig 1. Rx tórax: derrame pleural izdo.

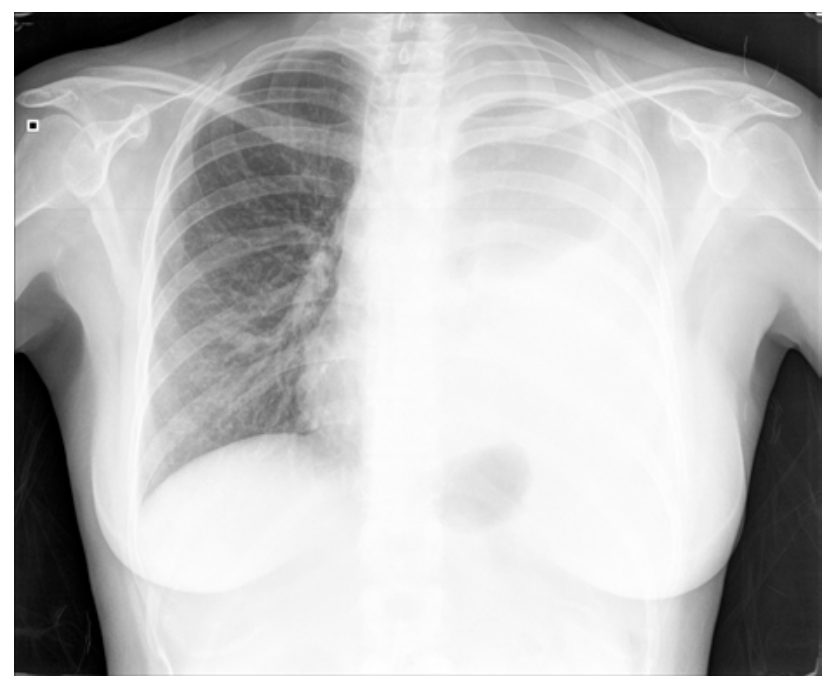

Estudios complementarios:

- Hemograma: Hb 10 mg/dL, 11.000 leucocitos con 86\% de neutrófilos, trombocitosis marcada (625.000 plaquetas) y una VSG de 131. Frotis sangre periférica con abundantes neutrófilos con hipersegmentación nuclear, anisocitosis y trombocitosis confirmada.

- Coagulación normal.

- Bioquímica: Función renal, perfil hepático, calcio, ácido úrico, $\mathrm{Na}+$ y K+ normales. Glucosa 96 mg/dL Proteínas $54 \mathrm{gr} / \mathrm{L}$. Albúmina $27 \mathrm{gr} / \mathrm{L}$. Colesterol total $248 \mathrm{mg} / \mathrm{dL}$. LDLC 152 $\mathrm{mg} / \mathrm{dL}$. HDLc $57 \mathrm{mg} / \mathrm{dL}$. Triglicéridos $194 \mathrm{mg} / \mathrm{dL}$. LDH 820 U/L y PCR $135 \mathrm{mg} / \mathrm{L}$.

- Serologías de VIH, VHC y VHC negativas.

- Auramina en esputo (X3): Negativas.

- La monitorización periódica del feto resultó normal y la toracentesis no traumática mostró un exudado linfocitario serohemático con ADA alto (68.7 U//L) 
Bioquímica y recuento celular del líquido pleural: Hematíes 50000 uL, leucocitos 1100 uL (76\% PMN), Glucosa 90 mg/dL, proteínas de 38 gr, LDH 1688 U/L y PH normal.

Con los hallazgos mencionados tratándose de una paciente joven en nuestra área sanitaria (Galicia) se estableció como hipótesis diagnóstica más probable la tuberculosis pleural. A la espera del resultado del Mantoux y resto de estudios en líquido pleural (citología, cultivo convencional, cultivo de micobacterias y PCR de micobacterias) se inició tratamiento con isoniazida, rifampicina, pirazinamida y etambutol. A pesar de la elevada sospecha diagnóstica, dado el contexto de la paciente, se contactó con el Servicio de Cirugía torácica para evacuación del derrame pleural y realización de biopsia pleural.

El Mantoux y la PCR de micobacterias en el líquido pleural fueron negativas. La citología negativa para malignidad. Pese al inicio del tratamiento antituberculoso y la evacuación del derrame pleural (1200 cc) desarrolló una evolución tórpida con persistencia de la fiebre, astenia intensa y disnea de mínimos esfuerzos. Finalmente siete días después del inicio del tratamiento, a las $35+6$ semanas de amenorrea, inicia dinámica uterina con rotura prematura de membranas (líquido amniótico meconial) y se decide la realización de una cesárea de recurso por riesgo de pérdida de bienestar fetal (sin posibilidad de control bioquímico) obteniéndose un recién nacido femenino de $1870 \mathrm{gr}$. Test de Apgar 9/10.

Pocas horas después de la cesárea, conociendo la evolución clínica y la ausencia de granulomas en la biopsia pleural, se realizó un TAC tóraco-abdomino-pélvico (fig 2) que mostró una gran masa mediastínica con extensa afectación pulmonar, derrame pleural izquierdo, pequeñas adenopatías axilares izquierdas, adenopatías en unión cervicotorácica, derrame pericárdico, nódulos pulmonares contralaterales, hepatoesplenomegalia y severa afectación renal bilateral. Hallazgos que sugieren una enfermedad de origen linfoproliferativo.

Fig 2. Tac toraco-abdomino-pélvico: gran masa mediastínica.

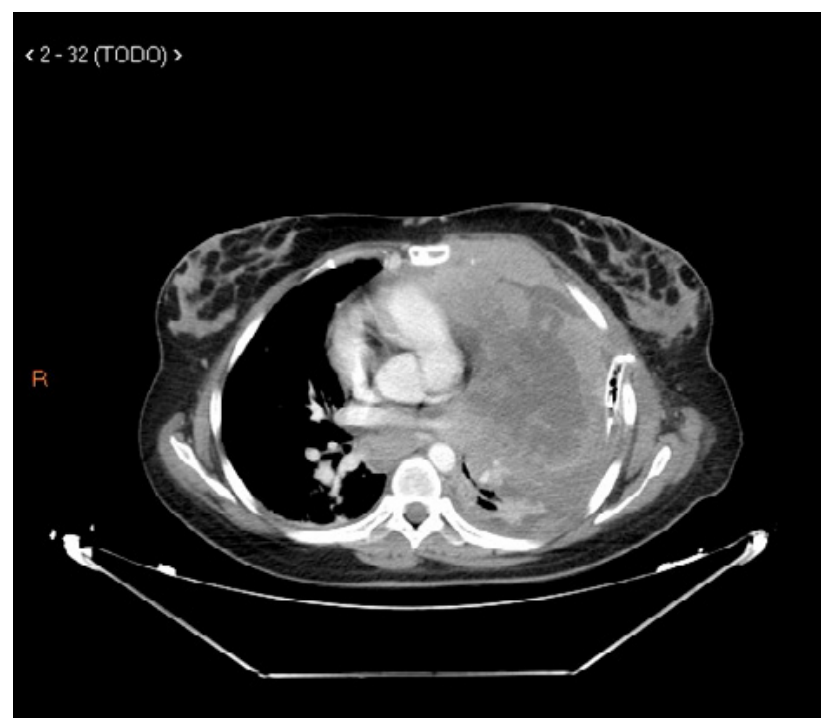

Pocos días después los hallazgos anatomopatógicos de la biopsia pleural confirmaron el diangóstico de Linfoma B difuso de células grandes. Se realizó biopsia de médula ósea y se procedió al traslado al centro de referencia para inicio de tratamiento con R-CHOP.

\section{Discusión}

En el contexto clínico referido con un exudado linfocitario con ADA un elevado nos surgen varias cuestiones que pasamos a discutir.
¿Con los resultados del Mantoux, cultivo y PCR de Micobacterias negativos se puede excluir el diagnóstico?

En absoluto. Hasta una tercera parte de los pacientes con tuberculosis pleural tienen un Mantoux negativo². En estos casos debería repetirse a las 2-6 semanas ya que puede positivizarse y ser útil para reforzar el diagnóstico. En pacientes VIH con recuento de CD4 menor a 200 células $/ \mathrm{mm}^{3}$ la negatividad es todavía más frecuente ${ }^{2}$.

Al ser el derrame pleural tuberculoso paucibacilar y producido fundamentalmente por una reacción de hipersensibilidad retardada convierte al cultivo de micobacterias en una técnica poco sensible (medio líquido sensibilidad 20-25\%) ${ }^{3}$. La infección por VIH y el predominio de PMN en fases tempranas de la enfermedad se relacionan con una mayor rentabilidad ${ }^{2-3}$. Las técnicas de amplificación de secuencias de ácido nucleicos específicas de tuberculosis permiten detectar la micobacteria en el líquido pleural en menor tiempo y con mayor frecuencia. Su sensibilidad no supera el $62 \%$ y la especificidad es del $98 \%{ }^{5}$.

En consecuencia tanto el cultivo como la PCR de micobacterias son técnicas útiles para confirmar el diagnóstico y no para excluirlo2-5.

\section{¿Se puede asumir el diagnóstico de derrame pleural tuberculoso? ¿Cuándo debe plantearse la realización de una biopsia pleural?}

En base al análisis de series españolas conocemos que puntos de corte de ADA pleural superiores a 40-45 UI/L tienen una sensibilidad cercana al $100 \%$ y una especificidad del $90 \%$ para definir la naturaleza tuberculosa del derrame pleural ${ }^{1}$.

En cualquier caso los clínicos debemos conocer que existen falsos positivos para un ADA elevado en líquido pleural. Algunos de fácil diferenciación (exudados con predominio PMN) como los derrames pleurales paraneumónicos o empiemas y otros mucho más infrecuentes como las neoplasias hematológicas. Sabemos que las falsas elevaciones de ADA entre los exudados linfocitarios no alcanzan el $4 \% 6$.

Por lo tanto en la práctica clínica podemos afirmar que cuando un paciente joven (< 40 años), especialmente en un área endémica, presenta un exudado linfocitario con un ADA pleural superior a $40 \mathrm{UI} / \mathrm{L}$ se asume el diagnóstico de tuberculosis pleural y se inicia tratamiento antituberculoso ${ }^{1}$. En esta situación conviene recordar que el diagnóstico de tuberculosis no es un diagnóstico de certeza sino de probabilidad. Así se deberá trasmitir al paciente y mantener un seguimiento estrecho. El diagnóstico de certeza de DPTB (derrame pleural tuberculoso) requiere la demostración de bacilos tuberculosos en el esputo, en el LP o en las muestras de biopsia pleural (BP), o bien la observación, en esta última de granulomas².

En consecuencia la excepcionalidad de nuestro caso no debe cambiar la práctica clínica diaria. Como hemos visto es muy discutible la necesidad de realización de biopsia pleural. Su indicación en nuestra paciente se estableció exclusivamente 
por criterio clínico. La necesidad de evacuación del derrame y utilizar un tratamiento antituberculoso con potenciales toxicidades en un periodo de gestación invitó a asumir la menor incertidumbre posible en el diagnóstico.

Puede justificarse la realización de una biopsia pleural fundamentalmente si nos encontrarnos en un país donde la prevalencia de tuberculosis sea baja ${ }^{2-3}$. Esta circunstancia motiva que el ADA mantenga un alto valor predictivo negativo pero un bajo valor predictivo positivo. Una segunda indicación estaría motivada por encontrarnos en zonas con alto nivel de resistencias micobacterianas donde tenga interés poder testar la sensibilidad a fármacos ${ }^{3}$. La tercera y última será una respuesta desfavorable de un paciente donde se haya instaurado tratamiento antituberculoso con un diagnóstico previo de probabilidad.

\section{Bibliografía}

1. Manejo práctico del derrame pleural. J.M Porcel-Pérez. An. Med. Interna (Madrid) Vol. 19, №4, pp. 202-208, 2002

2. Derrame pleural tuberculoso. Lucia Ferreiro, Esther San José y Luis Valdes. Arch Bronconeumol. 2014;50 (10): 435-443

3. Normativa sobre el diagnóstico y tratamiento del derrame pleural. Actualización. Victoria Villena Garrido et al. Arch. Bronconeumol. 2014;50 (6): 239-249

4. Etiología del derrame pleural: análisis de más de 3000 toracocentesis consecutivas José M. Porcel. Aureli Esquerda. Manuel Vives y Silvia Bielsa. Arch. Bronconeumol. 2014; 50 (5): 161-165.

5. Pai M, Flores LL, Hubbard A, Riley LW, Colford Jr JM. Nucleic acid amplification test in the diagnostic of tuberculous pleuritis: A systematic review and metaanalysis. BMC Infect Dis. 2004; 4:6.

6. Lee YCG, Rogers JT, Rodríguez RM, Miller KD, Light RW. Adenosine deaminase in nontuberculous lymphocytic pleural effusions. Chest 2001; 120: 356-61. 